\title{
Numerical modelling of agricultural products on the example of bean and yellow lupine seeds
}

\author{
Andrzej Anders*, Zdzisław Kaliniewicz, and Piotr Markowski \\ Department of Heavy Duty Machines and Research Methodology, University of Warmia and Mazury in Olsztyn, \\ Oczapowskiego 11, 10-736 Olsztyn, Poland
}

Received February 16, 2015; accepted September 17, 2015

\begin{abstract}
A b s t r a c t. Numerical models of bean seeds $c v$. Złota Saxa and yellow lupine seeds $c v$. Juno were generated with the use of a $3 \mathrm{D}$ scanner, the geometric parameters of seeds were determined based on the models developed, and compared with the results of digital image analysis and micrometer measurements. Measurements of seed length, width and thickness performed with the use of a micrometer, 3D scanner and digital image analysis produced similar results that did not differ significantly at $\alpha=0.05$. The micrometer delivered the simplest and fastest measurements. The mean surface area of bean seeds $c v$. Złota Saxa and yellow lupine seeds $c v$. Juno, calculated with the use of mathematical formulas based on the results of micrometer measurements and digital image analysis, differed significantly from the mean surface area determined with a $3 \mathrm{D}$ scanner. No significant differences in seed volume were observed when this parameter was measured with a 3D scanner and determined with the use of mathematical formulas based on the results of digital image analysis and micrometer measurements. The only differences were noted when the volume of yellow lupine seeds $c v$. Juno was measured in a $25 \mathrm{ml}$ liquid pycnometer. lupine

$\mathrm{K}$ e y w o r d s: 3D scanner, modelling shape, seed, bean,
\end{abstract}

\section{INTRODUCTION}

Companies operating in the agri-food sector continuously strive to introduce new products and technologies and to improve their quality. Models of agricultural product should deliver reliable results and should be relevant to the designed technological process (Datta and Halder, 2008). Three-dimensional models that describe a product geometric properties with high accuracy significantly contribute to the design and optimisation of technological processes. The traditional approach to modelling is based on the assump-

*Corresponding author e-mail: anders@uwm.edu.pl tion that the analyzed materials are homogeneous, isotropic and characterized by regular shapes (cylinder, sphere, cone, etc). The first step in computer modelling is to describe the geometric properties (dimensions, surface area, volume) of an agricultural product or a food product with a high degree of accuracy. Computer-aided design (CAD) and computational fluid dynamics (CFD) programs are used to model geometric parameters of foods and agricultural products (Verboven et al., 2004). Despite those advances, the shape, individual features and irregularities of an agricultural product are still difficult to render with high precision.

Numerical modelling of a product shape based on conventional methods is a laborious process, in particular in products with irregular shape (Goni et al., 2007). Fruit and seed dimensions are very often determined with the use of image analysis software and measuring tools such as calipers and micrometers (Frączek and Wróbel, 2006). Akaaimo and Raji (2006) analyzed Prosopis africana seeds and used a micrometer to determine the geometric parameters of the seeds. Ixtaina et al. (2008) relied on an electronic micrometer to determine the geometric parameters of chia (Salvia hispanica L.) seeds. Tylek (2012) described the distinctive properties of pedunculate oak seeds (Quercus robur L.) by analysing digital seed images in a dedicated application. The above author determined the geometric properties of acorns, calculated their shape factors and grouped the analyzed material into viability categories. Many authors relied on traditional measuring methods to determine the geometric parameters of seeds, including amaranth (Amaranthus cruentus L.) (Abalone et al., 2004), rapeseed (Brassica napus L.) (Cahsir et al., 2005), linseed

(C) 2015 Institute of Agrophysics, Polish Academy of Sciences 
(Linnum usitatissimum L.) (Coskuner and Karababa, 2007, Wiesnerova and Wiesner 2008), or buckwheat (Fagopyrum sagittatum Gilib) (Kram et al., 2007).

Erdogdu et al. (1998) relied on a machine vision system developed by Luzuriaga et al. (1997) to determine crosssectional parameters of shrimp for mathematical models of thermal processing methods. Crocombe et al. (1999) measured the surface area of meat chunks with the use of a laser scanner and used the results to model meat cooling times. Jancsok et al. (2001) developed numerical models of pears $c v$. Konferencja with the use of a computer vision system. Borsa et al. (2002) combined scanning and computed tomography techniques to determine the radiation dose absorbed by food components. Sabliov et al. (2002) proposed an image analysis method for determining the volume and surface area of axially symmetric agricultural products. Scheerlinck et al. (2004) generated a 3D model of strawberry fruit in a computer vision system and used the results to develop a thermal system for disinfecting fruit surfaces. Du and Sun (2006) and Zheng et al. (2006) developed an image analysis technique for determining the surface area and volume of beef joints. Eifert et al. (2006) developed a computer vision system for computing the surface area of irregularly shaped products. Kim et al. (2007) relied on computed tomography to develop 3D geometric models of food products with complex shape. Goni et al. (2008) proposed a method for modelling geometric parameters based on magnetic resonance imaging.

The cited studies indicate that high precision modelling of irregularly shaped products by image analysis requires the knowledge of various imaging techniques. 3D scanners can be used to develop 3D models and calculate the surface area and volume of food and agricultural products. The resulting numerical models can be used in computational fluid dynamics software to simulate various processes which take place during agricultural production and food processing. The objective of this study was to develop numerical models of bean seeds $c v$. Złota Saxa and yellow lupine seeds $c v$. Juno with the use of a 3D scanner, to determine the geometric parameters of the analyzed seeds based on the developed models, and to compare the findings with the results of digital image analysis and microtome measurements.

\section{MATERIALS AND METHODS}

The experimental material comprised bean seeds $c v$. Złota Saxa and yellow lupine seeds $c v$. Juno which were stored indoors at a temperature of $20 \pm 1{ }^{\circ} \mathrm{C}$ and $60 \%$ humidity. Seed moisture content was determined by drying at $120^{\circ} \mathrm{C}$. Bean and yellow lupine seeds were purchased from the Seed Centre in Olsztyn. Thirty undamaged seeds were randomly selected for the study from each product group. The length, width and thickness of the seeds were measured with a micrometer to the nearest $0.01 \mathrm{~mm}$. Bean and lupine seeds were scanned with a Plustek OpticPro ST24 scanner with 1200 dpi resolution. Individual seeds were scanned in two directions perpendicular to their length and thickness. To generate images of seeds for image processing a transparent film with a thin layer of glue had to be applied, which allowed the seed setting described above and scanning them twice. The resulting images were used to determine seed dimensions in ImageJ software (Rasband 1997-2014) with the accuracy of $d=0.01 \mathrm{~mm}$. The calculated dimensions were used to calculate the surface area and volume of seeds based on geometric formulas: (1) (McCabe et al., 1986), (2) and (5) (Gaston et al., 2002). Equations (2), (4), (5) and (6) are true only for ellipsoidal shape of seeds:

$$
\begin{gathered}
A=\pi D_{g}^{2}, \\
A_{g g}=\frac{\pi}{2} L L_{m}\left(\frac{L_{m}}{L}+\frac{1}{U} \arcsin (U)\right), \\
L_{m}=\frac{W+T}{2}, \\
U=\frac{\left(L^{2}-L_{m}^{2}\right)^{\frac{1}{2}}}{L}, \\
V_{g g}=\frac{\pi}{6} L W T,
\end{gathered}
$$

where: $A$ - seed surface area $\left(\mathrm{mm}^{2}\right), A_{g g}$ - seed surface area $\left(\mathrm{mm}^{2}\right), D_{g}$ - equivalent diameter of a seed $(\mathrm{mm})$, $L$ - seed length $(\mathrm{mm}), L_{m}$ - half of the sum of seed width and length $(\mathrm{mm}), W$ - seed width $(\mathrm{mm}), T$ - seed thickness $(\mathrm{mm}), U$ - coefficient determined by seed length, $V$ - seed volume $\left(\mathrm{mm}^{3}\right), V_{g g}$ - seed volume $\left(\mathrm{mm}^{3}\right)$.

The equivalent diameter $\left(D_{g}\right)$, sphericity index $(\phi)$ and shape factor $\left(R_{a}\right)$ were calculated with the use of the following formulas (Mohsenin, 1986):

$$
\begin{gathered}
D_{g}=(L W T)^{\frac{1}{3}}, \\
\phi=\frac{(L W T)}{L}, \\
R_{a}=\frac{W}{L} .
\end{gathered}
$$

Bean and lupine seeds were scanned with a NextEngine 3D laser scanner. Due to their small size, the seeds were mounted on a pin, and the pin was attached to a revolving table. Scanning density was 248 pixels per $\mathrm{mm}^{2}$. Numerical models were developed in the NextEngine ScanStudio HD PRO application (http://www.nextengine.com). The models were used to determine the surface area, volume, length, width and thickness of the seeds (Fig. 1) in the MeshLab application (http://meshlab.sourceforge.net/). Each seed was weighed on a Radwag WAA 100/C/2 scale to the nearest $0.0001 \mathrm{~g}$. Seed volume was determined in a $25 \mathrm{ml}$ liquid pycnometer. 
a
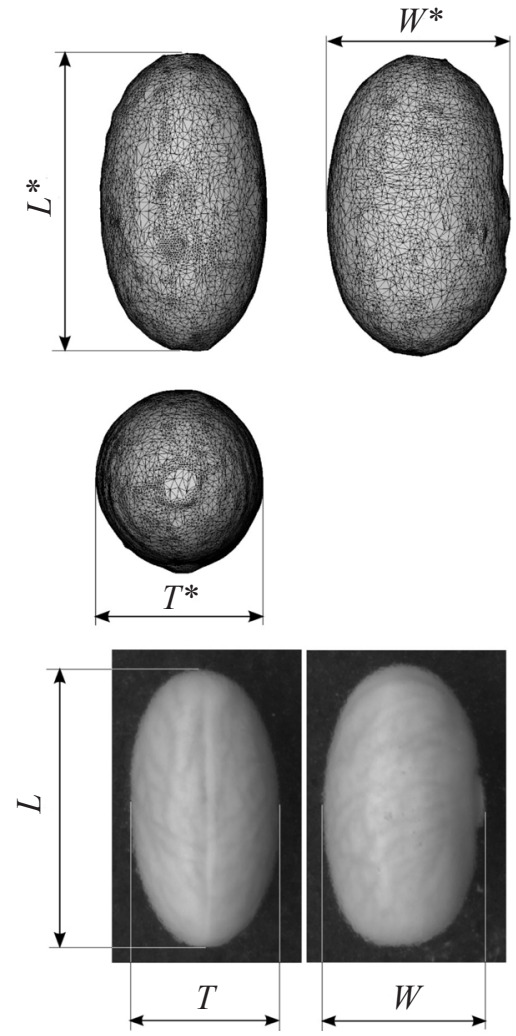

$\mathrm{b}$
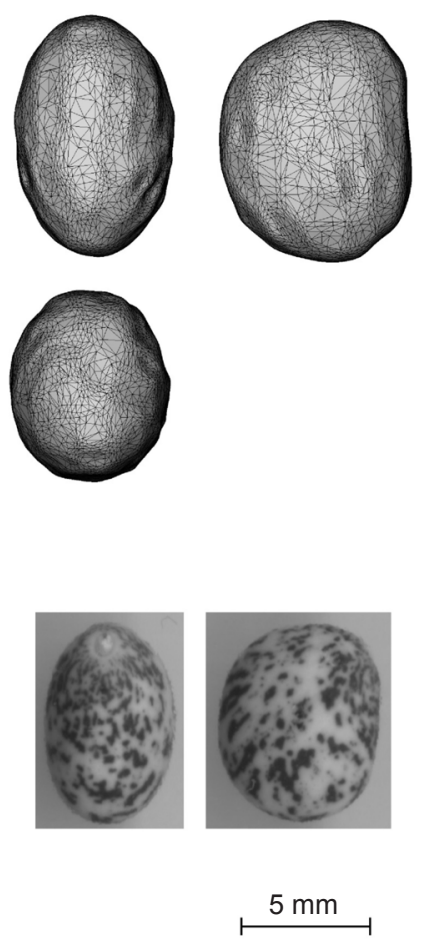

Fig. 1. Bean seeds $c v$. Złota Saxa (a), yellow lupine seeds $c v$. Juno (b) and the models developed based on 3D scans: $L-$ length, $W$ - width, $T$ - thickness. $L^{*}-$ length, $W^{*}$ - width, $T^{*}-$ thikness measured on numerical model.

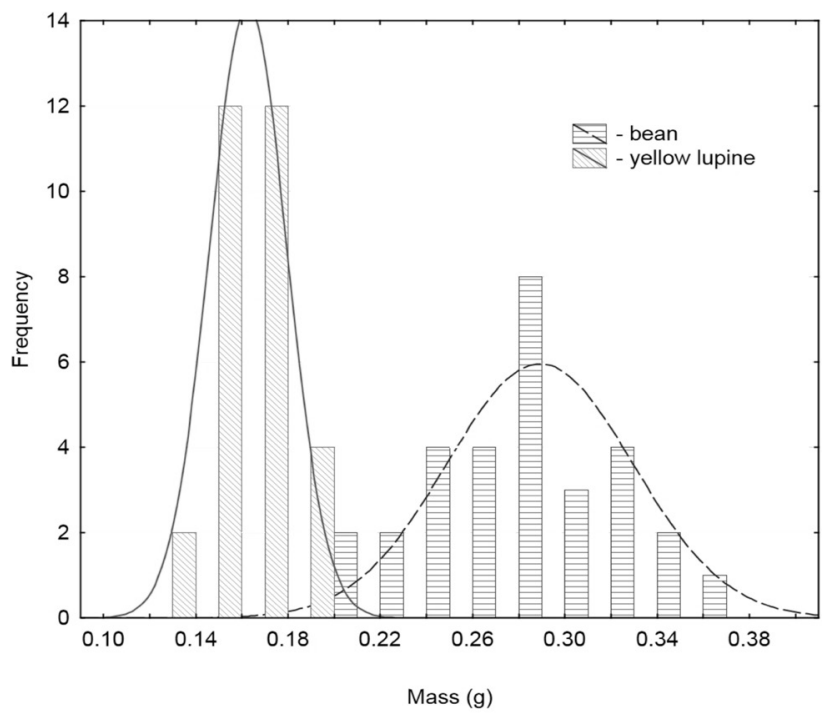

Fig. 2. Variability in the weight of bean seeds $c v$. Złota Saxa and yellow lupine seeds $c v$. Juno.

The results were processed statistically in the Statistica 10 application at a significance level of $\alpha=0.05$. The results of seed measurements performed with the use of a micrometer, image analysis software and 3D models were compared by one-way ANOVA. The analyzed variables were measurable and independent, therefore, the normality of distribution was determined in the Shapiro-Wilk test, and the homogeneity of variance was evaluated with the use of Levene test and the Brown-Forsythe test. Mean values were compared in Duncan multiple-range test.

\section{RESULTS AND DISCUSSION}

Bean seeds $c v$. Złota Saxa had an ellipsoidal shape and a light white colour, whereas yellow lupine seeds $c v$. Juno were characterized by a slightly flattened ellipsoidal shape and a light cream colour with numerous dark spots. Seed moisture content was determined at $13 \%$. Bean seeds cv. Złota Saxa were approximately $36-46 \%$ heavier than yellow lupine seeds $c v$. Juno. Bean and lupine seed weight data had approximately normal distribution (Fig. 2). In 3D scans, the mean surface area of bean seeds $c v$. Złota Saxa was $30 \%$ larger than the mean surface area of yellow lupine seeds $c v$. Juno. The mean volume of bean seeds $c v$. Złota Saxa determined with the 3D scanner was $40 \%$ higher than that of yellow lupine seeds $c v$. Juno.

The results of Duncan test revealed an absence of statistically significant differences in seed length determined with the micrometer, image analysis software and 3D scanner. No significant differences were observed when the above methods were applied to measure seed width and thickness (Table 1). The largest mean surface area of bean seeds was determined by Eq. (2) based on the results of 
T a b l e 1. Length, width and thickness of bean seeds and yellow lupine seeds

\begin{tabular}{|c|c|c|c|c|c|c|}
\hline \multirow{2}{*}{$\begin{array}{l}\text { Variable } \\
(\mathrm{mm})\end{array}$} & \multicolumn{2}{|c|}{ Mean } & \multicolumn{2}{|c|}{ Range } & \multicolumn{2}{|c|}{ Standard deviation } \\
\hline & bean seed & lupine seed & bean seed & lupine seed & bean seed & lupine seed \\
\hline$L^{m i k}$ & $10.68 \mathrm{a}$ & $7.50 \mathrm{a}$ & 2.47 & 2.07 & 0.55 & 0.39 \\
\hline$L^{A O}$ & $10.88 \mathrm{a}$ & $7.46 \mathrm{a}$ & 1.73 & 1.96 & 0.47 & 0.38 \\
\hline$L^{3 D}$ & $10.61 \mathrm{a}$ & $7.30 \mathrm{a}$ & 2.07 & 1.86 & 0.52 & 0.37 \\
\hline$W^{m i k}$ & $6.17 \mathrm{a}$ & $5.93 \mathrm{a}$ & 1.31 & 1.85 & 0.38 & 0.40 \\
\hline$W^{A O}$ & $6.25 \mathrm{a}$ & $5.98 \mathrm{a}$ & 1.46 & 1.47 & 0.39 & 0.36 \\
\hline$W^{3 D}$ & $6.17 \mathrm{a}$ & $6.03 \mathrm{a}$ & 1.36 & 1.43 & 0.40 & 0.33 \\
\hline$T^{m i k}$ & $5.94 \mathrm{a}$ & $5.12 \mathrm{a}$ & 1.58 & 1.11 & 0.37 & 0.25 \\
\hline$T^{H O}$ & $5.93 \mathrm{a}$ & $5.24 \mathrm{a}$ & 1.37 & 1.13 & 0.36 & 0.25 \\
\hline$T^{3 D}$ & $5.80 \mathrm{a}$ & $5.14 \mathrm{a}$ & 1.40 & 0.91 & 0.35 & 0.24 \\
\hline
\end{tabular}

Values in columns marked with identical letters do not differ significantly at $\mathrm{p} \leq 0.05$. mik- micrometer measurements, $A O-$ digital image analysis, $3 D-3 \mathrm{D}$ scanning.

T a b l e 2. Surface area of bean seeds and yellow lupine seeds

\begin{tabular}{|c|c|c|c|c|c|c|}
\hline \multirow{2}{*}{$\begin{array}{l}\text { Variable } \\
\left(\mathrm{mm}^{2}\right)\end{array}$} & \multicolumn{2}{|c|}{ Mean } & \multicolumn{2}{|c|}{ Range } & \multicolumn{2}{|c|}{ Standard deviation } \\
\hline & bean seed & lupine seed & bean seed & lupine seed & bean seed & lupine seed \\
\hline$A^{m i k}$ & $168.65 b$ & $117.25 \mathrm{a}$ & 64.48 & 31.02 & 16.43 & 8.62 \\
\hline$A_{g g}^{m i k}$ & $177.63 \mathrm{ac}$ & $119.72 \mathrm{a}$ & 65.84 & 33.56 & 16.89 & 8.87 \\
\hline$A^{A O}$ & $171.95 \mathrm{bc}$ & $119.47 \mathrm{a}$ & 70.35 & 35.01 & 16.51 & 8.90 \\
\hline$A_{g g}^{A O}$ & $181.49 \mathrm{a}$ & $121.62 \mathrm{ab}$ & 71.69 & 36.76 & 16.68 & 9.17 \\
\hline$A^{3 D}$ & $180.85 \mathrm{a}$ & $125.10 \mathrm{~b}$ & 60.56 & 39.92 & 15.87 & 9.83 \\
\hline
\end{tabular}

Explanation as in Table 1.

digital image analysis $\left(A_{g g}{ }^{A O}\right)$, and it did not differ significantly from the mean surface area determined from the $3 \mathrm{D}$ model $\left(A^{3 D}\right)$ or from the mean surface area calculated with the use of Eq. (2) based on the results of micrometer measurements $\left(A_{g g}{ }^{m i k}\right)$. Seed surface area calculated with Eq. (1) was significantly smaller when the results of digital image analysis $\left(A^{A O}\right)$ and micrometer measurements $\left(A^{m i k}\right)$ were used. No significant differences in bean volume where observed when this parameter was calculated with the use of Eq. (5) based on the results of micrometer measurements $\left(V^{m i k}\right)$ and digital image analysis $\left(V^{A O}\right)$ and when seed volume was determined with the use of a pycnometer $\left(V_{p}\right)$ and a $3 \mathrm{D}$ model $\left(V^{3 D}\right)$.

The largest mean surface area of yellow lupine seeds was obtained by $3 \mathrm{D}$ scanning $\left(A^{3 D}\right)$, and it did not differ significantly from the mean surface area calculated with the use of Eq. (2) based on the results of digital image analysis $\left(A_{g g}{ }^{A O}\right)$. A much smaller surface area was generated when the results of micrometer measurements $\left(A_{g g}{ }^{m i k}\right)$ where input in Eq. (1) and when the results of digital image analysis $\left(A^{A O}\right)$ and micrometer measurements $\left(A^{m i k}\right)$ were input in Eq. (2). Seed surface area calculated with the use of the above methods differed significantly from the remaining results (Table 2). The largest mean volume of yellow lupine seeds was determined in the pycnometer $\left(V_{p}\right)$, and it differed significantly from the remaining results. The observed variations could be attributed to the use of a $25 \mathrm{ml}$ liquid pycnometer and to the smaller dimensions of lupine seeds in comparison with bean seeds. No significant differences were noted between the mean volume of lupine seeds calculated from the 3D model $\left(V^{3 D}\right)$ and from Eq. (5) based on the results of digital image analysis $\left(V_{g g}{ }_{A O}\right)$ and micrometer measurements $\left(V_{g g}^{m i k}\right)$ (Table 3). 
T a b l e 3. Volume of bean seeds and yellow lupine seeds

\begin{tabular}{|c|c|c|c|c|c|c|}
\hline \multirow{2}{*}{$\begin{array}{l}\text { Variable } \\
\left(\mathrm{mm}^{3}\right)\end{array}$} & \multicolumn{2}{|c|}{ Mean } & \multicolumn{2}{|c|}{ Range } & \multicolumn{2}{|c|}{ Standard deviation } \\
\hline & bean seed & lupine seed & bean seed & lupine seed & bean seed & lupine seed \\
\hline$V_{g g}^{m i k}$ & $206.65 a$ & $119.62 \mathrm{a}$ & 117.75 & 47.80 & 30.06 & 13.25 \\
\hline$V_{g g}^{A O}$ & $212.72 \mathrm{a}$ & $123.04 \mathrm{a}$ & 130.51 & 54.68 & 30.65 & 13.85 \\
\hline$V_{p}$ & $216.38 \mathrm{a}$ & $135.37 b$ & 113.60 & 102.77 & 31.22 & 22.52 \\
\hline$V^{3 D}$ & $207.96 a$ & $125.84 \mathrm{a}$ & 107.89 & 57.58 & 28.37 & 14.55 \\
\hline
\end{tabular}

$V_{p}$ - pycnometer measurements. Other explanations as in Table 1.

T a b l e 4. Measurement results, geometric parameters and physical attributes of bean seeds and yellow lupine seeds $(\mathrm{N}=30)$

\begin{tabular}{|c|c|c|c|c|c|c|c|}
\hline \multirow[t]{2}{*}{ Variable } & \multirow[t]{2}{*}{ Unit } & Mean & Range & $\begin{array}{l}\text { Standard } \\
\text { deviation }\end{array}$ & Mean & Range & $\begin{array}{l}\text { Standard } \\
\text { deviation }\end{array}$ \\
\hline & & \multicolumn{3}{|c|}{ bean seed } & \multicolumn{3}{|c|}{ lupine seed } \\
\hline$D_{g}^{m i k}$ & \multirow{3}{*}{$(\mathrm{mm})$} & 7.31 & 1.40 & 0.35 & 6.10 & 0.80 & 0.22 \\
\hline$D_{g}^{A O}$ & & 7.39 & 1.51 & 0.35 & 6.16 & 0.89 & 0.22 \\
\hline$D_{g}^{3 D}$ & & 7.23 & 1.43 & 0.35 & 6.09 & 0.82 & 0.21 \\
\hline$R_{a}^{m i k}$ & \multirow{6}{*}{$(\%)$} & 57.88 & 13.07 & 3.45 & 79.28 & 27.57 & 6.31 \\
\hline$R_{a}^{A O}$ & & 57.51 & 14.35 & 3.41 & 80.22 & 21.77 & 5.00 \\
\hline$R_{a}^{3 D}$ & & 58.27 & 13.05 & 3.86 & 82.75 & 17.66 & 4.67 \\
\hline$\phi^{m i k}$ & & 68.53 & 11.17 & 2.63 & 81.51 & 17.64 & 3.65 \\
\hline$\phi^{A O}$ & & 67.92 & 11.02 & 2.45 & 82.62 & 15.83 & 3.19 \\
\hline$\phi^{3 D}$ & & 68.28 & 10.86 & 2.65 & 83.55 & 14.09 & 3.04 \\
\hline Mass & (g) & 0.288 & 0.150 & 0.040 & 0.162 & 0.060 & 0.017 \\
\hline
\end{tabular}

$D_{g}$ - geometric mean diameter, $R_{a}$ - aspect ratio, $\phi$ - sphericity. Other explanations as in Table 1.

If the largest mean equivalent diameter of bean seeds, calculated on the basis of the results of digital image analysis, equals $100 \%$, then the smallest mean equivalent diameter determined from $3 \mathrm{D}$ scans is smaller by $2 \%$. If the mean equivalent diameter of yellow lupine seeds, calculated on the basis of the results of digital image analysis, equals $100 \%$, then the smallest mean equivalent diameter determined from $3 \mathrm{D}$ scans is smaller by $1 \%$. The shape factor $\left(R_{a}\right)$ for bean seeds was the highest at $58.27 \pm 3.86 \%$ when calculated on the basis of on 3D measurements and the lowest at $57.51 \pm 3.41 \%$ when determined on the basis of the results of digital image analysis. The shape factor $\left(R_{a}\right)$ for yellow lupine seeds was the highest at $82.75 \pm 4.67 \%$ when calculated based on the results of $3 \mathrm{D}$ scans and the lowest at $79.28 \pm 6.31 \%$ when determined on the basis of the results of micrometer measurements. The highest mean sphericity index $\phi$ for bean seeds $c v$. Złota Saxa was calculated on the basis of the results of micrometer measurements, and the lowest - based on the results of digital image analysis. The mean sphericity index $\phi$ for yellow lupine seeds was the highest when determined from the numerical model, and the lowest when calculated on the basis of the results of micrometer measurements. The remaining results of measurements and calculations involving formulas 6,7 and 8 are presented in Table 4 .

To date, most researchers relied on micrometer or caliper measurements or digital image analysis to determine seed parameters (Ercisli et al., 2012; Seyedabadia et al., 2011; Shahin et al., 2006). The physical attributes of small objects, such as seeds of selected plant species, were not investigated based on 3D scans. Mieszkalski and Sołoducha (2008) developed 3D models of bean seeds $c v$. Aura with 
the use of mathematical formulas and randomly selected coefficients. The modelled volume was compared with the actual volume which was determined experimentally. Statistical analysis revealed differences between experimental and modelled parameters in the range of $0.07 \%$ to $3.04 \%$. Three-dimensional modelling is a non-destructive testing method, but shape factors and scaling parameters have to be selected individually for every seed. Wróbel (2011) developed a method for generating 3D models of triticale seeds in SolidEdge CAD software. Triticale seeds were embedded in resin, blocks were sliced in a microtome, seed cross-sections were scanned, the resulting images were processed and input into the SolidEdge application. The model was generated with the use of a function that combines previously acquired images of seed crosssections. The model preserves the distinctive geometric parameters (basic dimensions, curve radii) of seeds. The proposed method is destructive and time-consuming. In studies where geometric properties were determined from 3D scans, the analyzed objects were much larger than bean seeds or lupine seeds. Rahmi and Ferruh (2009) scanned apples, bananas, strawberries and pears. Siripon et al. (2007) used a 3D scanner (Atos, GOM, Germany) to acquire images of halved chickens.

\section{CONCLUSIONS}

1. Three-dimensional models developed with the use of a scanner can be used to analyse the geometric properties of seeds. Numerical models can be archived and applied in seed shape analyses in dedicated applications. Numerical models are not influenced by external factors that can lead to deformation and damage of live seeds during storage.

2. Measurements of seed length, width and thickness performed with the use of a micrometer, 3D scanner and digital image analysis produced similar results that did not differ significantly at $\alpha=0.05$. The micrometer delivered the simplest and fastest measurements.

2. The mean surface area of bean seeds $c v$. Złota Saxa and yellow lupine seeds $c v$. Juno, calculated with the use of mathematical formulas based on the results of micrometer measurements and digital image analysis differed significantly from the mean surface area determined in a $3 \mathrm{D}$ scanner.

3. No significant differences in seed volume were observed when this parameter was measured in a 3D scanner and determined with the use of mathematical formulas based on the results of digital image analysis and micrometer measurements. The only differences were noted when the volume of yellow lupine seeds $c v$. Juno was measured in a $25 \mathrm{ml}$ liquid pycnometer.

4. Three-dimensional models that incorporate the physical attributes of seeds, such as weight, deliver more accurate results in research studies.

\section{REFERENCES}

Abalone R., Cassinera A., Gaston A., and Lara M.A., 2004. Some physical properties of Amaranth seeds. Biosyst. Eng., 89, 109-117.

Akaaimo D.I. and Raji A.O., 2006. Some physical and engineering properties of Prosopis africana seed. Biosys. Eng., 95(2), 197-205.

Borsa J., Chu R., Sun J., Linton N., and Hunter C., 2002. Use of CT scans and treatment planning software for validation of the dose component of food irradiation protocols. Radiation Physics Chemistry, 63, 271-275.

Cahsir S., Marakoglu T., Ogut H., and Ozturk O., 2005. Physical properties of rapeseed (Brassica napus oleifera L.). J. Food Eng., 69, 61-66.

Coskuner Y. and Karababa E., 2007. Some physical properties of flaxseed (Linum usitatissimum L.). J. Food Eng., 78, 1067-1073.

Crocombe J.P., Lovatt S.J., and Clarke R.D., 1999. Evaluation of chilling time shape factors through the use of threedimensional surface modeling. In: Proc. 20th Int. Congress Refrigeration, IIR/IIF, September 19-24, Sydney, Australia.

Datta A.K. and Halder A., 2008. Status of food process modeling and where do we go from here (synthesis of the outcome from brainstorming). Comprehensive Reviews in Food Sci. Food Safety, 7, 117-120.

Du C.J. and Sun D.W., 2006. Estimating the surface area and volume of ellipsoidal ham using computer vision. J. Food Eng.,g 73, 260-268.

Eifert J.D., Sanglay G.C., Lee D.-J., Sumner S.S., and Pierson M.D., 2006. Prediction of raw produce surface area from weight measurement. J. Food Eng., 74, 552-556.

Ercisli S., Sayincib B., Karab M., Yildiz C., and Ozturk I., 2012. Determination of size and shape features of walnut (Juglans regia L.) cultivars using image processing. Scientia Horticulturae, 133, 47-55.

Erdogdu F., Balaban M.O., and Chau K.V., 1998. Modeling of heat conduction in elliptical cross-section: II. Adaptation to thermal processing of shrimp. J. Food Eng., 38, 241-258.

Frączek J. and Wróbel M., 2006. Methodic aspects of seed shape assessment (in Polish). Inżynieria Rolnicza, 12(87), 155-163.

Gastón Analía L., Abalone Rita M., and Giner Sergio A., 2002. Wheat drying kinetics. Diffusivities for sphere and ellipsoid by finite elements. J. Food Eng., 52(4), 313-322.

Goni S.M., Purlis E., and Salvadori V.O., 2007. Threedimensional reconstruction of irregular foodstuffs. J. Food Eng., 82, 536-547.

Goni S.M., Purlis E., and Salvadori V.O., 2008. Geometry modeling of food materials from magnetic resonance imaging. J. Food Eng., 88, 561-567.

Ixtaina V.Y., Nolasco S.M., and Mabel C.T., 2008. Physical properties of chia (Salvia hispanica L.) seeds. Industrial Crops and Products, 28, 286-293.

Jancsok P.T., Clijmans L., Nicolai B.M., and De Baerdemaeker J., 2001. Investigation of the effect of shape on the acoustic response of 'conference' pears by finite element modeling. Postharvest Biol. Technol., 23, 1-12.

Kim J., Moreira R.G., Huang Y., and Castell-Perez M.E., 2007. 3-D dose distributions for optimum radiation treatment planning of complex foods. J. Food Eng., 79, 312-321. 
Kram B.B., Woliński J., and Wolińska J., 2007. Comparative studies on geometric traits of nutlets with and without seed cover in Red Corolla buckwheat (in Polish). Acta Agrophysica, 9(3), 657-664.

Luzuriaga D.A., Balaban M.O., and Yeralan S., 1997. Analysis of visual quality attributes of white shrimp by machine vision. J. Food Sci., 62, 113-118.

McCabe W.L., Smith J.C., and Harriot P., 1986. Unit Operations of Chemical Engineering. McGraw-Hill, New York.

MeshLab Visual Computing Lab - ISTI - CNR, 2013. http://meshlab.sourceforge.net.

Mieszkalski L. and Sołoducha K., 2008. Modeling methods of sets of the solids seeds (in Polish). Postępy Techniki Przetwórstwa Spożywczego, 1, 39-44.

Mohsenin N.N., 1986. Physical Properties of Plant and Animal Materials. Gordon and Breach Sci. Press, New York, USA.

NextEngine User Manual, 2010. http://www.nextengine.com.

Rahmi U. and Ferruh E., 2009. Potential use of 3-dimensional scanners for food process modeling. J. Food Eng., 93, 337-343.

Rasband W.S., ImageJ, U. S. National Institutes of Health, Bethesda, Maryland, USA, http://imagej.nih.gov/ij/, 1997-2014.

Sabliov C.M., Bolder D., Keener K.M., and Farkas B.E., 2002. Image processing method to determine surface area and volume of axi-symmetric agricultural products. Int. J. Food Properties, 5, 641-653.

Scheerlinck N., Marquenie D., Jancsok P.T., Verboven P., Moles C.G., Banga J.R., and Nicolai B.M., 2004. A model- based approach to develop periodic thermal treatments for surface decontamination of strawberries. Postharvest Biol. Technol., 34, 39-52.

Seyedabadia E., Khojastehpourb M., Sadrniab H., and Saiedirade M.H., 2011. Mass modeling of cantaloupe based on geometric attributes: A case study for Tile Magasi and Tile Shahri. Scientia Horticulturae, 130, 54-59.

Shahin M.A., Symons S.J., and Poysa V.W., 2006. Determining soya bean seed size uniformity with image analysis. Biosys. Eng., 94 (2), 191-198.

Siripon K., Tansakul A., and Mittal G.S., 2007. Heat transfer modeling of chicken cooking in hot water. Food Res. Int., 40, 923-930.

Tylek P., 2012. Size and shape as separation properties of pedunculate oak seeds (Quercus robur L.) (in Polish). Acta Agrophysica, 19(3), 673-687.

Verboven P., De Baerdemaeker J., and Nicolai B.M., 2004. Using computational fluid dynamics to optimize thermal processes. In: Improving the Thermal Processing of Foods (Ed. P. Richardson), CRC Press, Boca Raton, FL,USA.

Wiesnerova D. and Wiesner I., 2008. Computer image analysis of seed shape and seed color for flax cultivar description. Computers Electronics Agric., 61, 126-135.

Wróbel M., 2011. $3 \mathrm{~d}$ reconstruction method of seeds in cad application (in Polish). Inżynieria Rolnicza, 6(131), 281-288.

Zheng C., Sun D.W., and Du C.J., 2006. Estimating shrinkage of large cooked beef joints during air-blast cooling by computer vision. J. Food Eng., 72, 56-62. 